\title{
Relational Sequence Networks as a Tool for Studying Gendered Mobility Patterns
}

\author{
Klaus Hamberger
}

\section{Introduction}

In recent years social network analysis and sequence analysis have become increasingly attentive to one another. This mutual interest stems from a profound affinity in their objects of study. In fact, sequences and networks are not so much separate domains as complementary dimensions of the same social reality-they belong together as time and space (see Abbott 1997). On the one hand, sequences are not just isolated linear series of events. A given event may participate simultaneously in several sequences, and a given type of event may occur several times in the same sequence. Put in context, sequences turn out to be mutually intersecting and potentially nonlinear walks in a comprehensive network of events or event types. On the other hand, social networks are more than static compilations of relations between individuals. Social relations are essentially processual, being created, transformed and dissolved in time, and each of these transformations constitutes an event in one or more sequences. Considered in their dynamic aspect, social networks turn out to be the cumulative results of a series of interconnected sequences. Sequence analysis thus logically leads to network analysis and vice versa.

One reason for the long-standing separation of the two approaches resides in the fact that they do not involve the same type of elements. The networks constructed from sequences are networks of events linked by ties of causation or succession. These event networks have been introduced in the study of narrative (Bearman et al. 1999; Bearman and Stovel 2000), in life course studies (Bison 2014; Fitzhugh et al. 2015) and in time use studies (Cornwell and Watkins 2015; Cornwell 2015, 2018). By contrast, the historical core domain of social network analysis has

K. Hamberger $(\bowtie)$

Laboratoire d'Anthropologie Sociale, Ecole de Hautes Etudes en Sciences Sociales, Paris, France e-mail: klaus.hamberger@ehess.fr 
been constituted by networks of (individual or collective) agents linked by ties of friendship, kinship, exchange, and so on. While sequence analysis has been recently applied to the study of the dynamics of agent networks (Stark and Vedres 2006, 2012), the sequences thus constructed consist of network positions (or positional states) rather than of events.

Clearly, the two approaches just described are complementary. Sequences consist of events that are linked to each other in the experience or narration of an agent, and social networks consist of agents who are connected to each other via their participation in a common event. Event networks and agent networks thus can be derived from one and the same bimodal network of agents and events. An integrated approach should analyze both kinds of networks simultaneously and study their mutual interaction, as each event transforms the agents' social environment, which in turn shapes the path of future events.

A natural candidate for exploring the potential of this integrated method is the domain of migration and mobility. On the one hand, mobility events are among the classical subjects of life course studies and sequence analysis. On the other hand, social network approaches, including longitudinal perspectives, are increasingly used in migration studies (Lubbers et al. 2010). However, these approaches generally deal with the relevance of migrants' social networks to social integration or transnational support, rather than with the migration process itself. Studies of the ways in which social networks influence migration processes (Liu 2013) remain rare, and rarer still are studies that examine how social networks and mobility interact (Wissink and Mazzucato 2018).

This paper adopts an integrated method which uses social network analysis both to define the alphabet of the sequences (as a set of types of relations) and to represent the sequences themselves (as oriented networks of relational types).

We will apply this method to examine the impact of gender on the patterns of local and regional mobility in South-east Togo. In this region of West Africa, both men and women are highly mobile, though for different reasons. The mobility of Togolese women is closely connected to their traditional role in trade (Cordonnier 1987) and the long-standing practice of migration of girls and young women to the capital Lomé as foster children and/or as domestic workers (Pilon and Ségniagbéto 2014). This pattern of non-matrimonial female mobility is complemented and reinforced by a virilocal post-marital residence pattern combined with traditionally high divorce and remarriage rates (Locoh and Thiriat 1995). Male mobility, on the other hand, has historically taken the form of circular labor migration, be it as farmhands, tenant farmers or lumberjacks to the plantations and forests of Western Togo, Ghana or Ivory Coast (in the case of the older generation), or more recently as unskilled workers to urban centres on the west African coast between Abidjan and Lagos. Even when rural emigration becomes long-term, the paternal home in the village frequently remains a refuge in case of unemployment, illness, and for retirement in old age, a pattern that is widespread in colonial and postcolonial West Africa (see e.g. Cordell et al. 1996). 
The network approach proposed in this paper is intended to improve understanding of the logic underlying these broad tendencies by examining the micromorphology of male and female migration trajectories and relational environments.

\section{Method}

\subsection{Basic Concepts}

Every event sequence can be represented as a path in a network, where nodes represent events and arcs represent immediate temporal succession. In Fig. 1 (left), for example, two simultaneous sequences (blue and red), are represented as paths through five events of four different types (A-D), two of which (B2 and B5) are common to both. By gathering similar events into larger classes, any such path will induce a sequence network, the nodes of which are not single events but event classes. Sequence networks of this sort are a variant of the networks used in life course analysis, such as life history graphs (Butts and Pixley 2004) or state transition graphs (Bison 2014). Since events of a given class can occur more than once in these networks, sequences now will no longer be linear paths but potentially nonlinear walks. Thus, in Fig. 1 (right), the networks corresponding to the sequences ABCBB (blue) and CBDAB (red) contain loops (BB), mutual dyads (BCB) and circuits (BDAB).

Events can be classified according to many different criteria, each giving rise to another kind of sequence network. For example, a classification by place of destination will result in the geographical network of migration routes. Here we are interested in people's movement in social space, so we shall classify events according to the relations that link the individuals involved.

Agents can participate in events in a variety of roles (such as "migrant", "host", and so on), and may be related to each other by relations that are polyadic ("A is child of B with C") and composite ("father's sister", "mother's employer" etc.). Complicated as they may appear, networks of this sort are not unfamiliar to

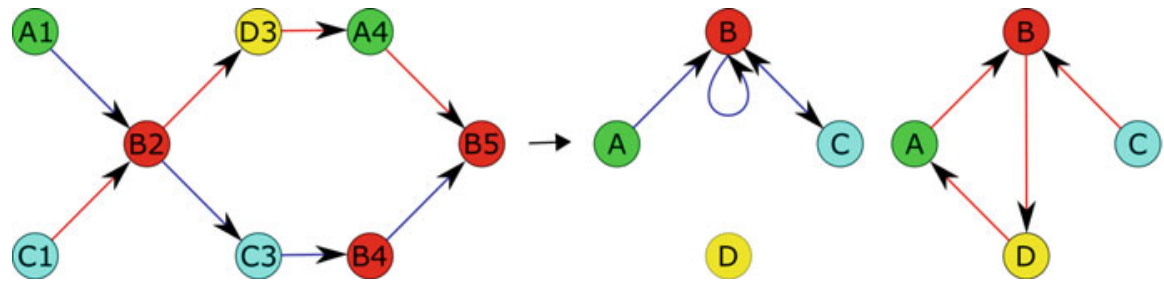

Fig. 1 Event networks (left) and sequence networks constructed from them (right). Nodes represent events (left) or event types (right), arcs represent immediate succession. Sequences are represented as (linear) paths in networks of events and as (nonlinear) walks in networks of event classes (sequence networks) 
social network analysis: kinship networks are commonly conceptualized as bimodal networks where "individuals" are linked to "families" by a variety of roles such as "father", "mother" and "child" (Batagelj and Mrvar 2008; Hamberger et al. 2011, 2014), and kinship relations comprise composite chains of parent-child or marriage ties. Now what we call "families" in kinship network theory are not so much sociological units but series of life course events (marriages and births) related to the same couple. We thus can conceive of "family events" (to which individuals are linked as "parent" or "child") in the same way as of "mobility events" (to which they are linked as "host" or "migrant") and vice versa. This similarity between kinship and mobility networks is more than formal. Marriage and divorce usually involve a change of residence for one of the partners, and every birth is in a sense a mobility event creating the starting point of an itinerary. Kinship and migration networks can accordingly be modeled as parts of an integrated bimodal network (see Fig. 2), where individuals and (mobility or family) events are represented as two different sets of nodes, and where the various roles that individuals play in these events are represented by different sets of edges.

The unimodal projections of this integrated bimodal network yield the one-mode networks usually studied in life course and kinship studies: networks of events linked to each other by the involved individuals, and networks of individuals linked to each other by shared events. For a given individual (ego), we can in this manner derive both the event sequence that constitutes his or her itinerary and the personal network that results from this itinerary.

The anchorage of both personal networks and event sequences in a single, multiplex bimodal network makes it possible to classify individuals and events by means of the relational circuits that emerge as mobility links combine with chains of other links (kinship, friendship, employment, and so). For example, individuals $\mathrm{C}$ and $\mathrm{H}$ in Fig. 2 are linked to each other as migrant and host (via mobility event 2), but also as brother's wife and husband's sibling (via birth events $3 \mathrm{a}$ and $3 \mathrm{~b}$ and marriage event 2), thus forming a relational circuit (marked blue in Fig. 2). Thus, we can first classify the individuals of ego's personal network by the relational chains that link them to ego (for example, host $\mathrm{H}$ as "brother-in-law"), and then classify the events of ego's itinerary by the relational classes that characterize individuals in certain roles (for example, mobility event 2 as "move to brotherin-law"). This relational classification of events in turn allows us to merge similar nodes of ego's itinerary, thus transforming it into a sequence network. Since the alphabet of sequence networks of this kind consists in classes of relations rather than in exogenous attributes (such as the motive for mobility events or the social class of the host), we distinguish them as relational sequence networks.

The specificity of relational sequence networks resides in using network techniques both for analyzing and for constructing sequences. They can be applied to any kind of sequences whose elements are pertinently characterized in terms of relations. In addition to migration studies, they may, for example, prove useful in the sociology of interactions, the morphology of folktales or the anthropology of ritual. The fact that we shall use them to study the impact of what may at first sight appear as an attribute of the individual-gender-does not contradict this 


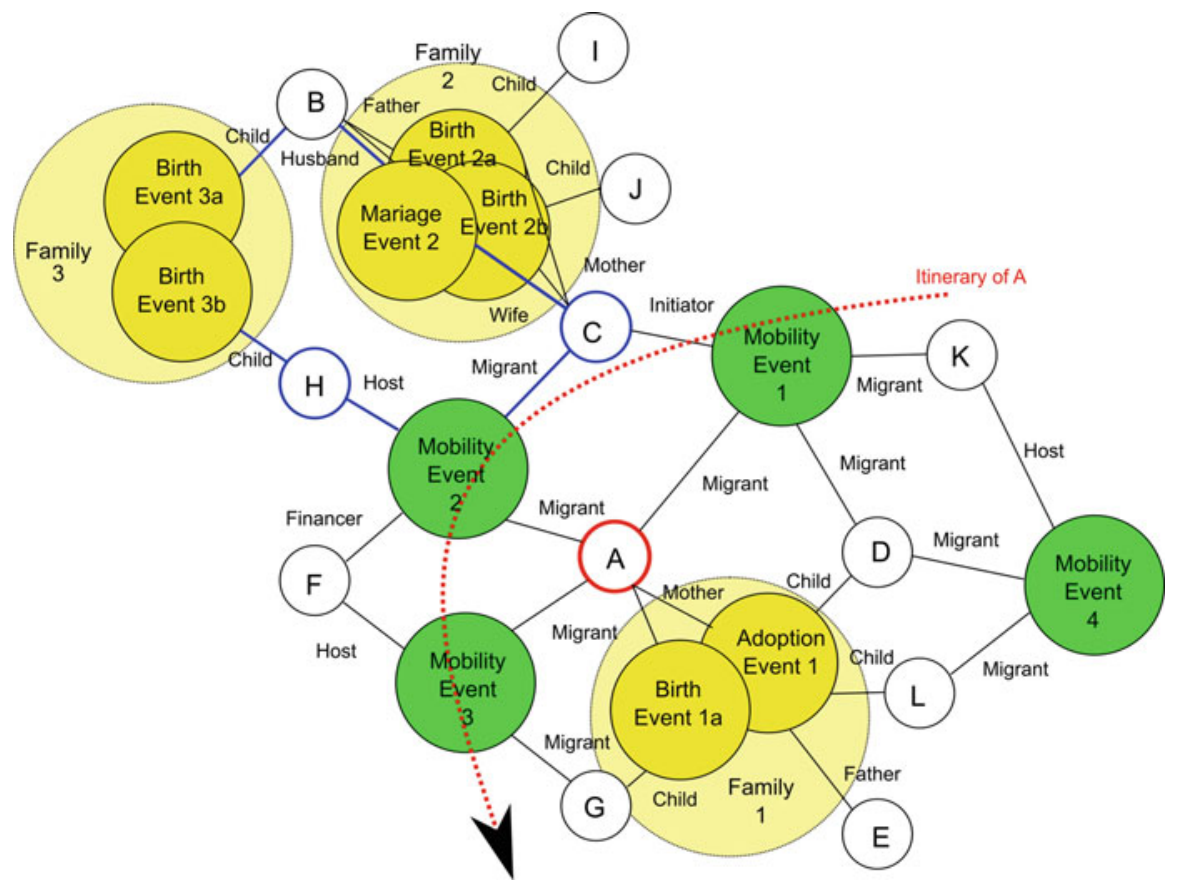

Fig. 2 An integrated kinship-mobility network. White nodes represent individuals; green and yellow relational nodes represent mobility and family events, respectively (family event nodes can be merged to form conventional family nodes, light-yellow). Edges linking individual to relational nodes correspond to the individual's roles in the event. Itineraries are represented as (dotted red) paths through successive mobility events

thoroughly relational orientation. Actually, the results of our analysis corroborate the now widely accepted approach that views gender itself in relational terms.

\subsection{Data}

The study is based on data collected in a field survey conducted in rural Southeast Togo between 2010 and 2015. ${ }^{1}$ The survey was centered on Afagnan-Gbléta, a large village whose core area has a population of around 4800 inhabitants (census

\footnotetext{
${ }^{1}$ Most of the interviews were conducted by the author in collaboration with Toussaint Yakobi and Komi Malou Kakanou during four stays (2009-10, 2010, 2012, and 2014-15). Forty-two interviews during autumn 2010 have been conducted by Ibitola Tchitou (URD, Lomé University) and the same collaborators.
} 
conducted by author in 2014). ${ }^{2}$ It is located in the maritime region of Togo, a very densely populated area (while it covers $10 \%$ of the national territory, $42 \%$ of the Togolese population live there). The region falls within the zone of West Africa with the highest intra-regional migration. Afagnan-Gbléta is situated close to the border of Benin, and the capital Lomé, at $81 \mathrm{~km}$ distance, can be reached within two hours by "bush taxi". The village is located close to a major West African migration route connecting the cities of Abidjan, Accra, Lomé, Cotonou, and Lagos. Short geographical distances, affordable transport, easy border crossings in the ECOWAS region and extended social and kinship networks all facilitate high transnational mobility.

The sample has been established in a two-step procedure. The first 60 interviews were conducted with persons drawn at random from the adult ( $>15$ years) residents of Afagnan-Gbléta (based on the village census effectuated in 2004/5) who were still alive and resident in Togo at the beginning of the study in $2010 .^{3}$ In the second step, we conducted interviews with all persons mentioned by the initial interviewees as having played a role in their migration biographies or as having been hosted by them, as far as these persons were alive, reachable within the perimeter of Southeast Togo, and willing to talk with us. Of the 876 living persons (from a total of 1111 persons named), we were able to interview 328 persons on their own and on their non-adult children's trajectories, which resulted in 449 additional biographies. The total snowball sample thus contains 509 migration biographies (260 male and 249 female).

Migration biographies were collected through retrospective semi-directive interviews. We asked interviewees to recall all migratory events leading to a change of residence for more than three months ${ }^{4}$ from birth to the present (time of the interview, last update of information in 2014/15), and to describe the context, motive and course of each migratory event. In particular, we collected information (name, relation and contact) on the persons who received ego (hosts), accompanied ego (co-migrants), initiated ego's displacement (initiators) and financed ego's journey (financers). All other persons mentioned in the context of the migration event were equally noted (others). This set of names was complemented by a list of the interviewee's parents, spouses and children. Finally, we asked each interviewee to name all those persons for whom he or she had acted as a host.

This dataset is completed by a genealogical and residential dataset (about 50,000 individuals including the deceased) collected during three censuses of the village of Afagnan-Gbléta (2004/5, 2009/10 and 2014/15) as part of ongoing ethnographic

\footnotetext{
${ }^{2}$ According to 2010 official census data, Afagnan-Gbléta counts 12,411 inhabitants (5916 males and 6495 females) when all its hamlets are included.

${ }^{3}$ Information on present life status and residence were obtained after the draw, so that there were 76 draws in all (35 women/41 men) because $6(3 / 3)$ had died, 5 (1/4) had moved abroad, one woman refused the interview, and 4 young men appeared in the sample due to errors concerning their age.

${ }^{4}$ This restriction was meant to exclude short-term stays for funerals, visits or holidays. In fact, the problem was rather that even year-long stays, for example at the natal home after childbirth, were often considered by interviewees as temporary absences not to be mentioned, and discovered only afterwards when dealing with the children's itineraries.
} 
fieldwork (see Hamberger 2011). Most of the remote kinship relations (such as "father's mother's brother's daughter") and mediated non-kinship relations (such as "friend's employer") were thus not (only) directly reported by interviewees but computed from data stemming from numerous different oral sources. The anonymized dataset is available on the Kinsources repository (permanent link: https://www.kinsources.net/kidarep/dataset-275-watchi-2017.xhtml).

The total snowball sample has only an auxiliary value for the analysis. Besides the bias in favor of local and circular migration trajectories owing to the geographical limits of the survey, the snowball technique introduces a systematic bias in favor of connected and mobile persons, who have a higher chance of playing a role in the itineraries of the first interviewees. All comparative data concerning the overall sample thus are likely to overestimate mobility and network cohesion. Moreover, not being composed of independent observations, the snowball sample cannot be analyzed with standard statistical techniques. Most of our analyses are therefore restricted to the random sample of 60 itineraries. The remaining 449 itineraries serve essentially to construct the ego-centered social spaces and sequence networks of these 60 cases. For the purpose of illustration, four of these cases will be considered in further detail below.

\subsection{Software Tools}

All analyses used in this paper have been made using the open source software Puck version 2.3.50 (Hamberger et al. 2014), which can be downloaded at http:// www.kintip.net (source code at http://sourceforge.net/projects/tip-puck/). Initially developed for the study of kinship networks, Puck contains, from its 2.2 version onwards, a package (org.tip.puck.sequences) for the study of longitudinal data. The networks of Figs. 3, 6, 7, and 8 have been visualized with the software Pajek (http:// mrvar.fdv.uni-lj.si/pajek/) from files produced by Puck. The detailed procedures for reproducing the analyses of the paper are described in the document accompanying the Watchi dataset on the Kinsources repository (see above).

\section{Results}

\subsection{Personal Networks}

In order to introduce the analyses presented in the remainder of this paper, let us begin by considering one empirical case example. We have chosen the itinerary of Betty, ${ }^{5}$ a middle-aged female domestic worker with transnational experience (Benin

\footnotetext{
${ }^{5}$ First names of the four example individuals have been changed.
} 
Table 1 Betty's (10683) itinerary as sequence of successive mobility events. Relational roles of hosts and co-migrants are indicated in brackets. Village and quarter names have been replaced by numbers

\begin{tabular}{|c|c|c|c|c|c|}
\hline & Year & Age & Start and end places & Hosts & Co-migrants \\
\hline 0 & 1961 & 0 & $>\mathrm{V} 1$ & 10690 [MOTHER] & \\
\hline 1 & 1973 & 12 & V1 > Lomé-1 & 41315 [RELATIVE] & \\
\hline 2 & 1985 & 24 & Lomé-1 > Lomé-1 & $\begin{array}{l}41319 \text { [EMPLOYER] } \\
41320 \text { [EMPLOYER] }\end{array}$ & \\
\hline 3 & 1986 & 25 & Lomé-1 > V2 & $\begin{array}{l}10687 \text { [FATHER] } \\
10690 \text { [MOTHER] }\end{array}$ & \\
\hline 4 & 1987 & 26 & V2 > Lomé-2 & 41318 [SIBLING] & \\
\hline 5 & 1988 & 27 & Lomé-2 > Lomé-3 & 10682 [SPOUSE] & \\
\hline 6 & 1990 & 29 & Lomé-3 > V3 & 10678 [AFFINE] & \\
\hline 7 & 1991 & 30 & V3 > Lomé-3 & 10682 [SPOUSE] & 10685 [CHILD] \\
\hline 8 & 1992 & 31 & Lomé-3 > Cotonou & 41321 [SPOUSES_EMPLOYER] & $\begin{array}{l}10682 \text { [SPOUSE] } \\
10684 \text { [CHILD] } \\
10685 \text { [CHILD] }\end{array}$ \\
\hline 9 & 2000 & 39 & Cotonou $>$ V3 & 10682 [SPOUSE] & $\begin{array}{l}10684 \text { [CHILD] } \\
10685 \text { [CHILD] } \\
10686 \text { [CHILD] } \\
10695 \text { [RELATIVE_UTERINE] } \\
\end{array}$ \\
\hline 10 & 2006 & 45 & V3 > Lomé-1 & 39670 [AFFINE, MASTER] & \\
\hline 11 & 2007 & 46 & Lomé-1 > Lomé-4 & 41322 [AFFINE, EMPLOYER] & \\
\hline 12 & 2007 & 46 & Lomé-4 > Dakar & 41323 [EMPLOYER] & \\
\hline 13 & 2008 & 47 & Dakar > Lomé-1 & 39670 [AFFINE, MASTER] & \\
\hline 14 & 2008 & 47 & Lomé-1 > Lomé-5 & 41324 [EMPLOYER] & \\
\hline 15 & 2009 & 48 & Lomé-5 > Lomé-6 & 41325 [EMPLOYER] & \\
\hline 16 & 2010 & 49 & Lomé-6 > Lomé-6 & 56354 [LANDLORD] & 10684 [CHILD] \\
\hline 17 & 2013 & 52 & Lomé-6 > Lomé-7 & 56751 [LANDLORD] & \\
\hline 18 & 2013 & 52 & Lomé-7 > Mali & 56750 [LANDLORD] & \\
\hline
\end{tabular}

and Senegal, most recently Mali). Table 1 represents the sequence of successive mobility events, each of which links her to one or more hosts, ${ }^{6}$ some of them also to co-migrants. Their respective identity numbers are listed in the last two columns of the table.

In order to study the social networks shaping (and shaped by) individual trajectories, we first have to look at the way in which the relations created by a mobility event (linking a migrant to his or her hosts, co-migrants, and so on)

\footnotetext{
${ }^{6}$ While birth mothers constitute by convention the starting points of all itineraries (and sequence networks), they have not been explicitly coded as hosts at birth so as to avoid trivial results of relational censuses and personal network analyses.
} 
coincide with other direct or indirect relations between these individuals. ${ }^{7}$ We have considered seven main types of relations: (1) kinship ties up to the fourth canonic degree for consanguines (ex. third cousins) and up to the first degree for affines (ex. fathers-in-law); (2) non-genealogical kinship (including both kinship ties for which the genealogical chain is unknown and those for which probably no such chain exists, such as the "father's child" relationship established by reference to a common locality of origin); (3) friendship (including relations between colleagues, fellow workers and classmates); (4) apprenticeship; (5) initiation (which includes a more or less prolonged stay at a vodu priest's home); (6) employment; and (7) landlord-tenant relationship. Since the latter generally implies the absence of a preexisting social relation, hosts are classified as "unrelated" only when they have accommodated ego without payment.

The relations linking Betty to her hosts and co-migrants are given in brackets in the last two columns of Table 1. As we can see, Betty has been received by her parents (1 event, without counting the birth event), her brother (1), her husband (3), a relative (1), three affines (4), one of whom is also an employer (1) and another a (future) master (2), various unrelated employers (4), her husband's employer (1), and various landlords who rented her a room (3). She has mainly travelled alone, and has only occasionally been accompanied by one or more children (3), a uterine niece (1), and her husband (1).

Table 2 shows the frequencies of these various kinds of host and co-migration relations for all itineraries of the total snowball sample ( 509 cases). The numbers indicate the number of itineraries in which the migrant-host or the co-migrant relation coincides at least once with a social relation of the respective type.

A look at the types of hosts and co-migrants occurring in male and female itineraries instantly reveals some marked differences (but also some important similarities). The virilocal orientation of residence in Togolese society is clearly evident: almost all adult women have moved to their husbands or affines on at least one occasion while the reverse trajectory concerns only a small minority of men. ${ }^{8}$

A more remarkable feature is the marked tendency to return to the parental home. This circular pattern holds not only for men who hold land rights in their natal family, but also for women, who systematically return to it before (re)marrying.

For both men and women, relatives outside the immediate family circle are at least as important as parents in the role of hosts-with a slight preference of male and female for agnatic and uterine relatives, respectively.

\footnotetext{
${ }^{7}$ Though these relations generally precede the mobility event, there are some cases of relations that have been created after the move (e.g. by marrying a host's relative, or by starting an apprenticeship with the host as master).

${ }^{8}$ The definition of 'host' is here bound to land and residence rights rather than to residential precedence. Thus, a wife returning to her husband has been classed as returning to her marital home, while a man returning to his wife has been categorized as returning to his own (or parental, or rented) home. This is a reasonable assumption to make in the rural context but may introduce unwarranted male bias into data collected in an urban setting.
} 
Table 2 Types of relations to hosts and co-migrants occurring in male and female itineraries. Figures indicate the number of (male, female, all) itineraries where a host or co-migrant in the corresponding relation to ego appears in at least one event. Percentages refer to the total number of itineraries concerned (260 male, 249 female, 509 all)

\begin{tabular}{|c|c|c|c|c|c|c|c|c|c|c|c|c|}
\hline \multirow[b]{2}{*}{ Relation type } & \multicolumn{6}{|c|}{ Migrant-host relations } & \multicolumn{6}{|c|}{ Co-migrant relations } \\
\hline & M & $\%$ & $\mathrm{~F}$ & $\%$ & All & $\%$ & M & $\%$ & $\mathrm{~F}$ & $\%$ & All & $\%$ \\
\hline Own property & 52 & 20.0 & 8 & 3.2 & 60 & 11.8 & & & & & & \\
\hline Parents/Parental home & 167 & 64.2 & 149 & 59.8 & 316 & 62.1 & 88 & 33.8 & 79 & 31.7 & 167 & 32.8 \\
\hline Spouse/Marital home & 2 & 0.8 & 162 & 65.1 & 164 & 32.2 & 90 & 34.6 & 77 & 30.9 & 167 & 32.8 \\
\hline Sibling & 67 & 25.8 & 56 & 22.5 & 123 & 24.2 & 117 & 45.0 & 98 & 39.4 & 215 & 42.2 \\
\hline Child & 2 & 0.8 & 14 & 5.6 & 16 & 3.1 & 72 & 27.7 & 116 & 46.6 & 188 & 36.9 \\
\hline Relative & 162 & 62.3 & 161 & 64.7 & 323 & 63.5 & 77 & 29.6 & 71 & 28.5 & 148 & 29.1 \\
\hline Agnatic relative & 68 & 26.2 & 54 & 21.7 & 122 & 24.0 & 34 & 13.1 & 27 & 10.8 & 61 & 12.0 \\
\hline Uterine relative & 64 & 24.6 & 80 & 32.1 & 144 & 28.3 & 24 & 9.2 & 27 & 10.8 & 51 & 10.0 \\
\hline Affine & 37 & 14.2 & 79 & 31.7 & 116 & 22.8 & 44 & 16.9 & 48 & 19.3 & 92 & 18.1 \\
\hline Landlord & 116 & 44.6 & 52 & 20.9 & 168 & 33.0 & & & & & & \\
\hline Friend & 36 & 13.8 & 12 & 4.8 & 48 & 9.4 & 40 & 15.4 & 8 & 3.2 & 48 & 9.4 \\
\hline Employe & 39 & 15.0 & 29 & 11.6 & 68 & 13.4 & 1 & 0.4 & 0 & 0.0 & 1 & 0.2 \\
\hline Master & 51 & 19.6 & 9 & 3.6 & 60 & 11.8 & 7 & 2.7 & 0 & 0.0 & 7 & 1.4 \\
\hline Vodu priest & 5 & 1.9 & 24 & 9.6 & 29 & 5.7 & & & & & & \\
\hline Public (Hotel, Market) & 19 & 7.3 & 5 & 2.0 & 24 & 4.7 & & & & & & \\
\hline State or NGO & 14 & 5.4 & 5 & 2.0 & 19 & 3.7 & & & & & & \\
\hline Unrelated & 16 & 6.2 & 1 & 0.4 & 17 & 3.3 & & & & & & \\
\hline Unknown & 10 & 3.8 & 12 & 4.8 & 22 & 4.3 & 9 & 3.5 & 2 & 0.8 & 11 & 2.2 \\
\hline
\end{tabular}

Residence with a master during apprenticeship is more relevant for boys than for girls, who are more frequently employed as market helpers or domestic workers. ${ }^{9}$ By contrast, it is mainly girls who as initiates spent a (today much reduced) period of residence with a vodu priest. The male predominance in monetary relations to landlords may partly reflect a tendency among interviewees to represent the husband as the contracting party even if both spouses contribute to the rent (we did not verify who pays). By contrast, stays in state- or NGO-owned facilities (caserns, schools, hospitals) or in hotels are largely restricted to the educated male elite.

While the gender inflection of host-migrant relations concerns mainly the marital tie, its impact on co-migration becomes manifest in the parental tie: children move with mothers rather than with fathers. By contrast, travelling with non-kin (friends and fellow workers) is more frequent for men than for women. Predictably (since our data include infant migration), siblings are among the most frequent co-migrants.

After this first inspection of the positions that make up the social space in which a person navigates, let us now take a closer look at the structure of this space. We

\footnotetext{
${ }^{9}$ In cases where masters and employers were relatives, the work relationship has been given precedence over kinship when constructing sequence networks.
} 
shall confine our analysis to the personal networks of the 60 initial interviewees. Clearly, our picture of these networks is incomplete since neither the dead nor most of those living abroad could be interviewed about their own relations, forcing us to rely on ego's indications for them. This data collection bias reinforces ego's memory bias, so that the resulting networks are in a sense doubly "ego-centered", being most dense in ego's actual spatial and temporal neighborhood.

The nodes of the networks are made up of all persons who played a role as host, co-migrant, initiator or financer in ego's itinerary, but not those persons for whom ego played only the role of a host. Also, the network does not contain those named as "others", whose role consists in providing the general context. Composite kinship links mediated by persons who are themselves in the network have not been represented by direct arcs so as to preserve their mediated character. ${ }^{10}$

Figure 3 shows four example networks, where relation types are indicated by different colors. Besides Betty's personal network (upper left), we have selected the networks of Omar, a male tailor circulating between Afagnan-Gbléta and the Benin-Nigerian frontier; Sosime, an elderly female trader who has returned to Afagnan-Gbléta after an itinerary including transnational commuting between Lomé and Lagos; and Aloesso, a former goldsmith who spent his youth living in his elder brother's household at Lomé.

We are interested in the importance of different relations for the network structure, be it as intermediaries for indirect relations or as nuclei of locally cohesive clusters. The first aspect can be measured by the betweenness centrality ${ }^{11}$ of the individuals so related to ego; the second by the fact that these individuals play a locally central role (measured by node degree) ${ }^{12}$ in one of the connected components into which the network decomposes if ego is removed. In Fig. 3, the individuals (other than ego) with the highest betweenness centrality have been marked by bold borders, and connected components (after removal of ego) have been encircled. As can be seen, Betty's network can be decomposed into 10 components, centered respectively around her parents (1), her husband (1), an employer (3), a relative (2) and a landlord (3), where all but one of the three last mentioned categories constitute single-element components. The largest component (9 nodes) is the marital component centered around the husband, who is also the individual with the highest betweenness centrality (14\%) after ego (85\%).

Table 3 indicates the number of itineraries in which each of the considered relations characterizes the most central alter in the whole network or in one of its components (in addition, we have indicated the mean size and the maximal number of the respective components centered on this relation).

\footnotetext{
${ }^{10}$ For example, if ego has migrated with his or her mother and maternal grandmother, the network will contain the grandmother but no direct link between her and ego.

${ }^{11}$ The betweenness centrality of a node (Freeman 1977) is measured as the normalized number of shortest paths running through it.

${ }^{12}$ The (in-/out-) degree of a node is defined as the number of nodes to which it is linked (by incoming/outgoing arcs).
} 

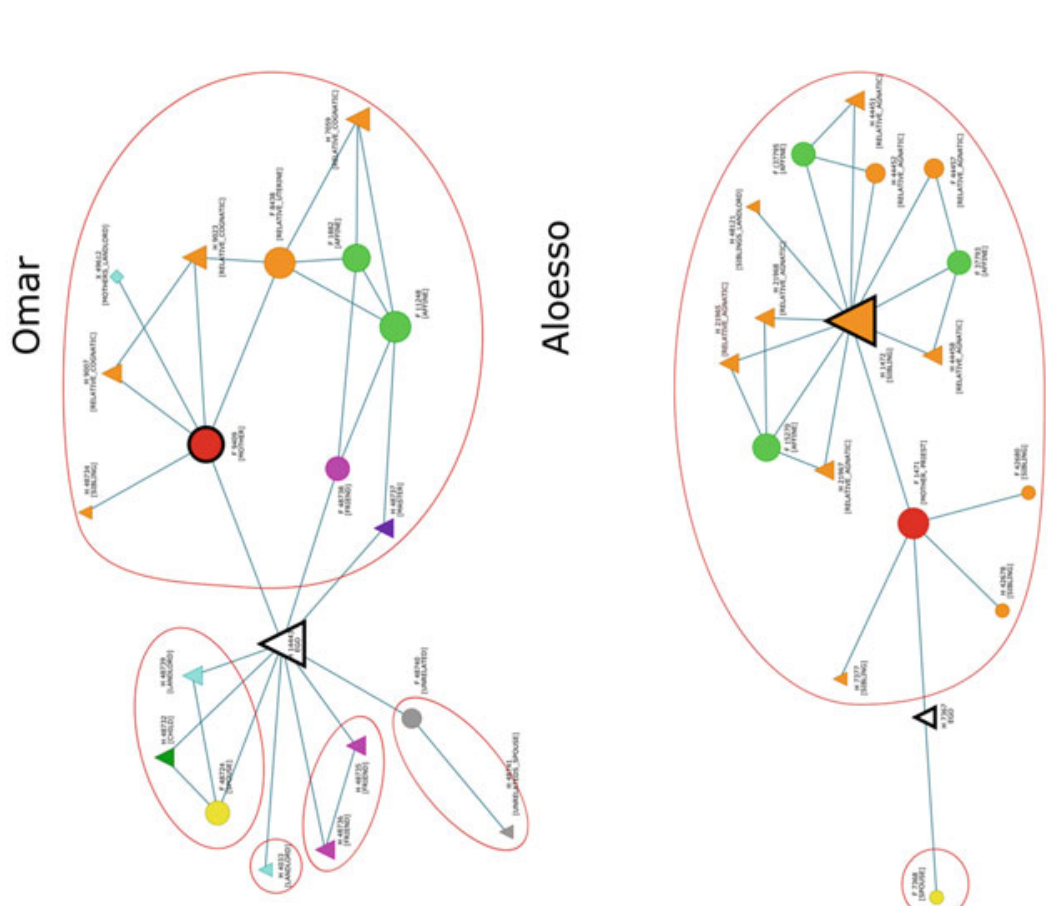

훌

过

$\exists \dot{0}$

뭉

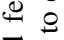

ज :

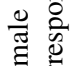

융

뫃

के

o

웜

ㅎํㅇ

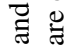

要

冚

(1)

紊
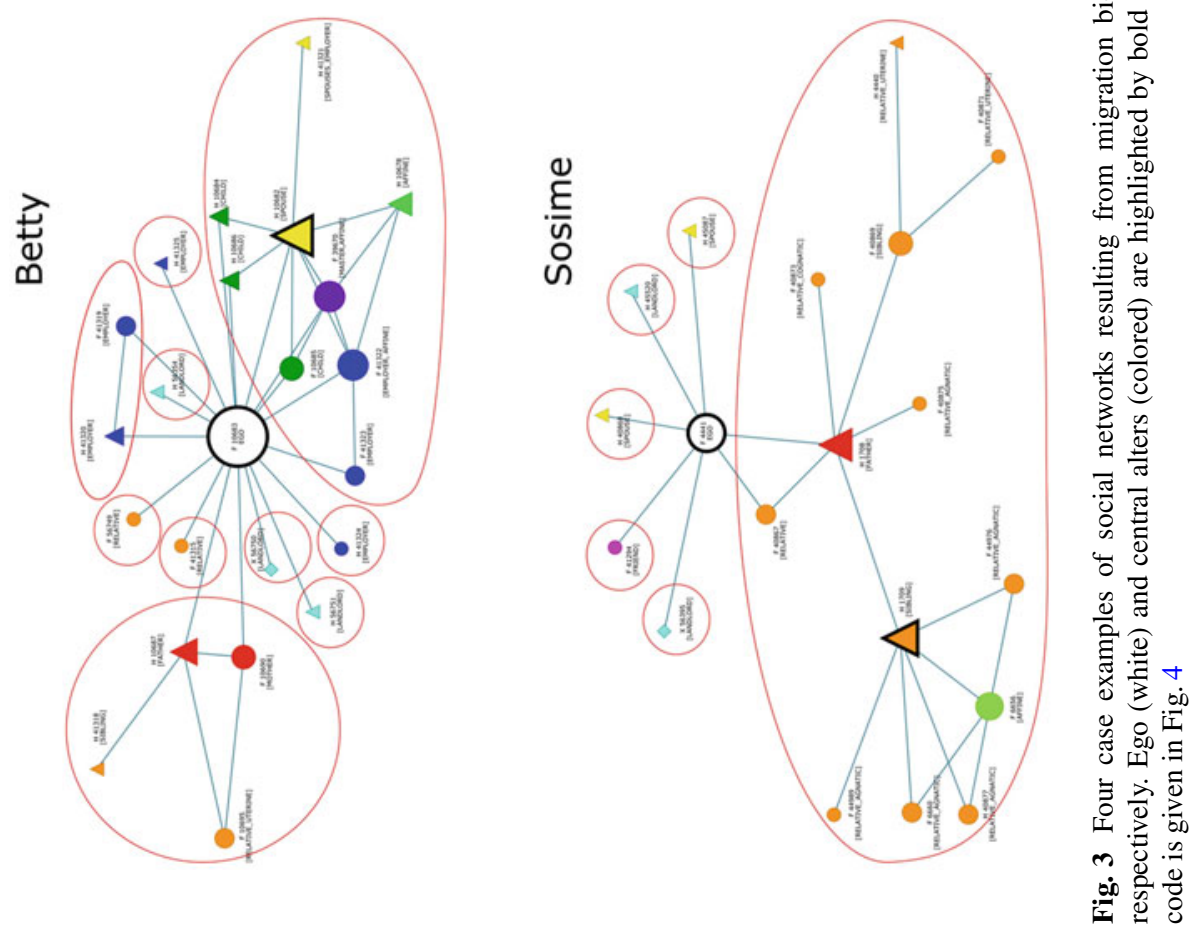
Fig. 4 Color code for Figs. 3, 6, 7, and 8

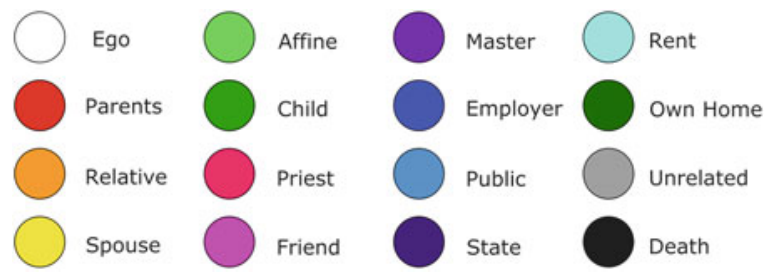

Table 3 Globally and locally central relations. Figures indicate the (absolute and percentage) numbers of personal networks where the individual(s) most central in the network or in one of its components have the corresponding relation with ego. The table also indicates the mean size and the maximal number of such components; if there is more than one, mean component size refers to the largest. Percentages refer to the total number of itineraries concerned ( 30 male, 30 female, 60 in all)

\begin{tabular}{|c|c|c|c|c|c|c|c|c|c|c|c|c|}
\hline & \multicolumn{4}{|c|}{$\begin{array}{l}\text { Maximal (non-ego) } \\
\text { centrality }\end{array}$} & \multicolumn{8}{|c|}{ Component nucleus } \\
\hline & \multicolumn{2}{|c|}{ Male } & \multicolumn{2}{|c|}{ Female } & \multicolumn{4}{|c|}{ Male } & \multicolumn{4}{|c|}{ Female } \\
\hline & $\#$ & $\%$ & $\#$ & $\%$ & $\#$ & $\%$ & Mean size & Max nr & $\#$ & $\%$ & Mean size & Max nr \\
\hline Father & 15 & 50.0 & 10 & 33.3 & 10 & 33.3 & 5.1 & 1 & 12 & 40.0 & 5.5 & 1 \\
\hline Mother & 11 & 36.7 & 4 & 13.3 & 7 & 23.3 & 6.6 & 1 & 2 & 6.7 & 4.0 & 1 \\
\hline $\mathrm{Fa}+\mathrm{Mo}$ & & & & & 5 & 16.7 & 4.8 & 1 & 3 & 10.0 & 5.0 & 1 \\
\hline Spouse & 3 & 10.0 & 9 & 30.0 & 15 & 50.0 & 4.1 & 1 & 23 & 76.7 & 3.7 & 3 \\
\hline Sibling & 2 & 6.7 & 2 & 6.7 & & & & & & & & \\
\hline Friend & 2 & 6.7 & & & 9 & 30.0 & 1.1 & 7 & 1 & 3.3 & 1.0 & 1 \\
\hline Relative & 3 & 10.0 & 3 & 10.0 & 9 & 30.0 & 3.1 & 2 & 4 & 13.3 & 4.3 & 2 \\
\hline Affine & & & 1 & 3.3 & & & & & 2 & 6.7 & 8.0 & \\
\hline Landlord & 1 & 3.3 & & & 14 & 46.7 & 1.0 & 9 & 6 & 20.0 & 1.0 & 4 \\
\hline Master & 1 & 3.3 & & & 5 & 16.7 & 1.2 & 2 & & & & \\
\hline Vodu priest & & & 1 & 3.3 & & & & & 2 & 6.7 & 1.0 & 1 \\
\hline Employer & 2 & 6.7 & & & 7 & 23.3 & 1.6 & 3 & 4 & 13.3 & 1.0 & 3 \\
\hline
\end{tabular}

We now see that the various relations that we previously examined in isolation operate in quite different ways in organizing ego's social space. On the one hand, there are relations that function as connectors: they give rise to other relations which they mediate, and thus become centers and nuclei of large connected componentsthis is the case of kinship relations, in particular the parental ties that mediate all others. On the other hand, there are relations that operate as divisors: they neither integrate themselves into an existing social space nor lead to other relations, but tend to form numerous small components. These "atomizing" relations are usually mediated by money, linking ego to landlords, masters or employers. However, some relations of this kind may mediate relations between fellow apprentices or working colleagues (counted as "friends" in our classification).

The extremes of these two types of relations - one centralizing a singular large component, the other leading to multiple marginal isolates-constitute a polarity which to a certain extent characterizes the male mobility pattern. On the one hand, 
the kinship core, while important for both genders, is more fundamental for male networks: $50 \%$ of male networks, as opposed to $33 \%$ of female networks, are centered around the father (who forms the local center of a component in $50 \%$ of both male and female networks). On the other hand, the atomized components of rent and wage relations occur both more frequently and in greater number in male than in female networks. The typical male social space is centered around a single large kinship base from which repeated expeditions are undertaken to a variety of rapidly changing social and spatial destinations. The rural-urban circular migration also largely follows this radial pattern, and even those who are in stable employment (teachers, policemen, etc.) are mostly implicated in continuous displacements.

Not all relations, however, fit into this polarity. On the one hand, there are relations that are both unique and isolated, such as the relation of initiate to vodu priest. On the other hand, there is the marital relation, which is both relatively central and gives rise to cohesive components structured around nuclear families, but which, in this region of West Africa, is typically multiple. While men can have several wives at the same time, women generally have several husbands at different times in the course of their lives. Contrary to men, for women each new marriage involves a displacement, and mediates a series of new relations that play a role for their future migrations. Each new husband thus becomes the nucleus of a (frequently large) component of the wife's mobility space.

The gender-specific occurrence of different relations noted previously thus corresponds to different relational logics in the structuring of social space, which is evident in the contrastive overall morphologies of male and female personal networks. On average, female networks are more cohesive than male networks: they contain half as many isolates (1.3 vs 3 ), their average number of components is lower (2.8 vs 4.1$)$, and their concentration-measured as the Herfindahl index of component shares-is higher $(0.58$ vs 0.52$)$. However, this concentration does not imply the presence of one dominant giant component, but of two or several components of roughly equal importance. As a corollary, ego's own centrality is generally lower for female than for male egos ( 0.48 vs 0.62$)$. The more or less (de-)centered position of ego can be expressed more precisely in considering the normalized difference between the (betweenness) centralities of ego and the most central alter. This index of ego's differential centrality ranges from $-100 \%$ for maximal marginality to $+100 \%$ for maximal centrality, where $0 \%$ indicates a central position shared by ego and one or more central alters. Differential centrality is closely correlated to the concentration of ego's personal network (see Fig. 5). The more disintegrated the network (after removal of ego), the higher ego's centrality (with the migrant teacher as an extreme example), and the more integrated the network, the higher ego's marginality (with the foster child at the other extreme).

While Fig. 5 shows the moderate average tendency of female networks towards higher concentration and lower ego centrality, it also shows a great diversity. To explore further this diversity, let us consider our four case examples, each of which represents different combinations of differential centrality and concentration 


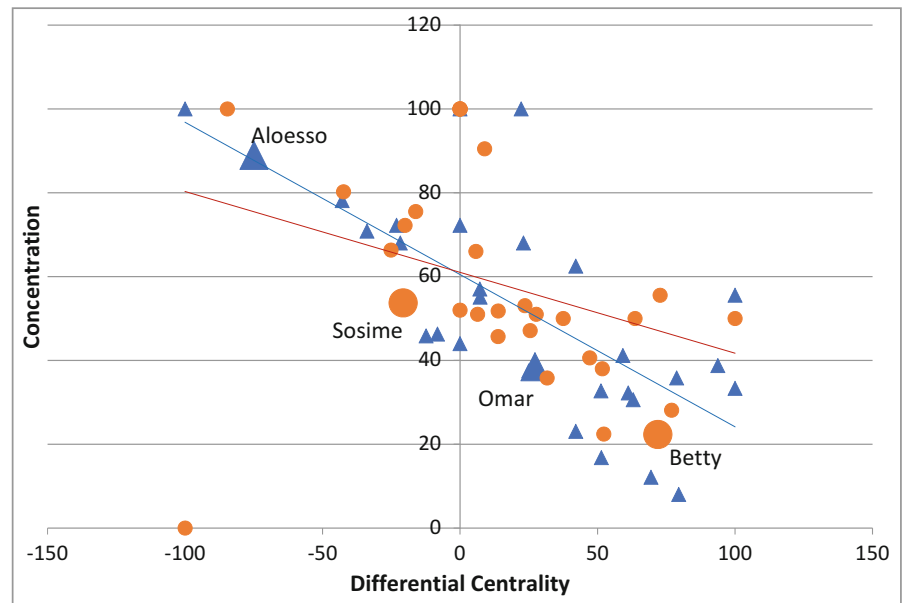

Fig. 5 Differential centrality ( $x$-axis) and concentration ( $y$-axis) of the 60 personal networks of the random sample, including the four example cases. Blue triangles and red circles (and the corresponding blue and red tendency lines) refer to male and female networks, respectively

Table 4 Four case examples (individual attributes and personal network indicators)

\begin{tabular}{|c|c|c|c|c|c|c|c|c|c|}
\hline \multirow[b]{2}{*}{ Case } & \multicolumn{4}{|c|}{ Personal attributes } & \multicolumn{5}{|c|}{ Personal network indicators } \\
\hline & Gender & Age & $\begin{array}{l}\text { Occupa- } \\
\text { tion }\end{array}$ & $\begin{array}{l}\text { Family } \\
\text { status }\end{array}$ & Size & $\begin{array}{c}\text { Compo- } \\
\text { nents } \\
\text { (Isolates) }\end{array}$ & $\begin{array}{c}\text { Diffe- } \\
\text { rential } \\
\text { centrality }\end{array}$ & $\begin{array}{c}\text { Concen- } \\
\text { tration }\end{array}$ & $\begin{array}{l}\text { Central } \\
\text { alter }\end{array}$ \\
\hline Betty & $\mathrm{F}$ & 49 & $\begin{array}{l}\text { domestic } \\
\text { worker }\end{array}$ & $\begin{array}{l}\text { widow, } 3 \\
\text { children }\end{array}$ & 23 & $10(7)$ & 72 & 22.3 & Spouse \\
\hline Omar & M & 28 & tailor & $\begin{array}{l}2 \text { wives, } 2 \\
\text { children }\end{array}$ & 20 & $5(1)$ & 27.3 & 38.5 & Mother \\
\hline Sosime & $\mathrm{F}$ & 79 & trader & $\begin{array}{l}\text { widow, } \\
\text { divorced, no } \\
\text { children }\end{array}$ & 19 & $6(5)$ & -20.3 & 53.7 & Father \\
\hline Aloesso & M & 44 & $\begin{array}{l}\text { farmer } \\
\text { (former } \\
\text { goldsmith) }\end{array}$ & $\begin{array}{l}1 \text { wife, } 3 \\
\text { children }\end{array}$ & 18 & $2(1)$ & -74.9 & 88.9 & Brother \\
\hline
\end{tabular}

(Table 4 and Box 1). As one can see from Betty's and Aloesso's networks, cases of female solitary long-distant migration (yielding ego-centered, dispersed networks), or of male dependent family migration (yielding alter-centered, concentrated networks), are not unusual. 
Betty's network represents the combination of high ego centrality and relatively low network integration typical for persons whose itineraries are shaped by high mobility outside the kinship network, such as teachers or soldiers, but also, as in the present case, female domestic workers. Besides the numerous isolated components she traversed in the course of her professional migrations, her social space also contains several more cohesive groups, one of which, organized around her husband, also channeled her professional itinerary.

Omar's network likewise represents a relatively poorly integrated social network, but ego's relative centrality here is much less pronounced. We again meet the combination of several cohesive components - an initial uterine network centered around the mother, a transnational migrant trader, a component of friends, and a marital component-each of which has been important for professional connections. There are fewer isolated components, also due to ego's younger age. The mother's central position results from the fact that she constitutes the bridge between the two spaces (Togo and Benin) between which ego is oscillating.

Sosime's network combines high network integration with a moderate decentralised position of ego. The high cohesion of the network results from the fact that it is largely composed of (active and passive) fosterage ties with close kin. After having been hosted by paternal relatives in childhood, she has subsequently hosted (and been accompanied by) a whole series of young female relatives, including the daughters of her former hosts, to be again hosted, in old age, by one of her former foster children. However, being childless herself, all these links are mediated through other members of her personal network, so that the high network concentration does not imply a high centrality of ego, but of the relative (her father) who serves as an intermediary. (Since fosterage typically implies a host-migrant relation, we did not include it into the relations of the personal network so as to avoid circularity. Otherwise, Sosime's centrality would have been considerably higher.)

Aloesso's network represents the extreme case of a highly integrated network where ego holds a marginal position (expressed by highly negative differential centrality). In fact, the network's main component is actually not his but his elder brother's network, while the second, marital component has not developed into a larger network, since ego's marriage coincided with a definitive return to sedentary life in the natal village.

Box 1 Personal network analysis of the four example cases

\subsection{Sequence Networks}

After having examined in a synchronic manner the way personal networks have been shaped by (and have shaped) people's itineraries, let us now turn to the question how these itineraries run through the various positions of these networks. We shall construct the corresponding relational sequence networks by classifying mobility events according to the type of relation or relational chain that links ego to his or her host. To facilitate comparison, we have used a very coarse classificatory grid, which, for example, lumps together all relatives other than the immediate parents into a single category, ${ }^{13}$ and generally does not distinguish between different instances of the same relational type (such as "landlord"), with the only exception of spouses. Even so, except for the three individuals who have never left their natal social

\footnotetext{
${ }^{13}$ The software Puck allows for any kind of precision for the classification of kinship chains.
} 

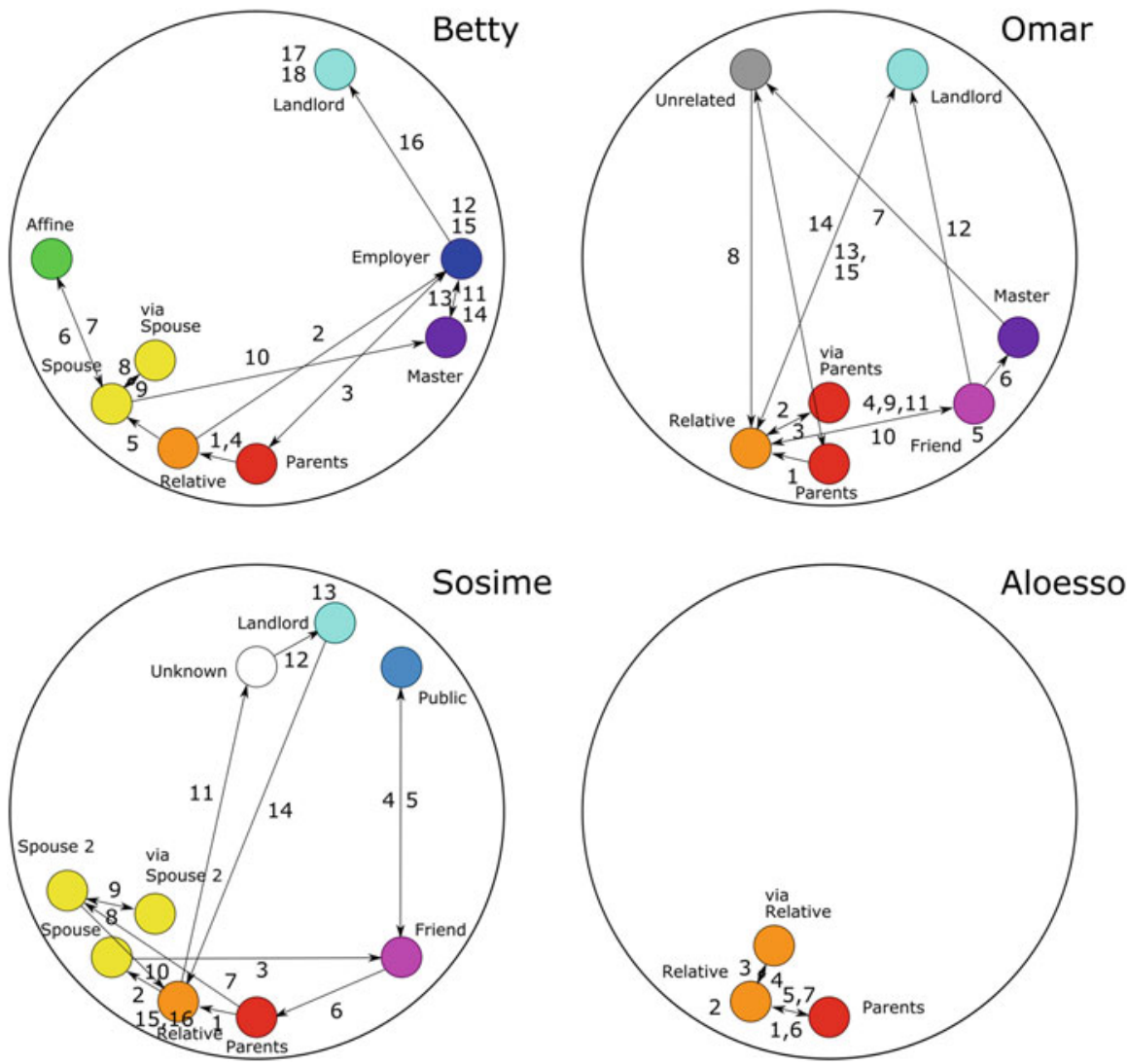

Fig. 6 Relational sequence networks of the four case examples. Nodes represent classes of events according to the type of relation between migrant and host; arcs indicate immediate succession of events of the corresponding type, numbered by order of occurrence in the itinerary. Numbers attached to nodes refer to loops (moves to new hosts within the same relational category). For the color code see Fig. 4

environment, the sequence networks of the 60 individuals of our random sample are all different from each other.

Figure 6 shows the relational sequence networks of our four example individuals, briefly discussed in Box 2. Each relational type is represented by a node. All itineraries start at the parental node (at the bottom), since the host of the first "mobility event" (birth) is by definition the birth mother.

The network representation of these relational sequences allows us to compare them by means of network-analytic indicators. Some of these indicators concern the local position of nodes - such as in- and outdegrees, which measure the diversity of relations that precede or succeed a given relation, or betweenness centralities, which 


\begin{abstract}
Aloesso's sequence network is the most simple: an oscillation between the parental home and a close maternal relative (his brother in Lomé), connected to an intermittent oscillation between the brother and a variety of hosts to whom Aloesso was only related by his brother's mediation. The simplicity of the sequence network is the corollary of Aloesso's marginality in the social network, by virtue of which the (orange) "relative" and "via relative" nodes absorb the quasi-totality of events.
\end{abstract}

Omar's sequence network is more complex: it also starts with a move to non-parental relatives (first his maternal aunt in Benin, later his maternal grandmother and uncles in the village), but he uses these positions as springboards to engage with hosts of various types linked to his professional education and activity, such as masters, compatriots, strangers, and finally landlords.

A quite similar basic pattern can be observed in Betty's case: again starting with a move to a maternal aunt, she soon begins staying with various employers and landlords. However, this professional network is completed by a series of social positions to which she accedes via marriage: her husband, the husband's employers, and the husband's relatives (i.e. her affines). Note that this marital network is not distinct from, but integrated into the professional network: just as was the case with her own relatives during her youth, her husband's relatives are at the same time her employers or mediate her relations to future employers.

The most complex sequence network is Sosime's, who combines a long-term shift from the paternal home (where she is hosted first by her father then by her brother) to several successive husbands with oscillating movements to and from the landlords of the capital and the friends and market places of Nigeria. The brother's home serves as a constant haven of return in these movements, and also as the crossroad where she "picks up" the young female relatives who accompany her through the various stages of her career as a trader.

Box 2 Sequence network analysis of the four example cases

indicate the importance of relations as transitions from or to other relations. ${ }^{14}$ Others concern the global network structure-such as the number of dyads or cycles, which correspond to the frequency of direct or indirect returns to relations that appeared earlier in the itinerary. In Betty's case, for example, her frequent but intermittent accommodation by her employers is evident in the fact that the employer relation has both the highest betweenness centrality and the highest outdegree and forms part of the two oriented cycles of her sequence network. (For a detailed discussion of network indicators such as density, centralization or homophily in sequence analysis, see Cornwell 2018).

To which extent do these sequence patterns follow a gendered logic? To answer this question, we can proceed in two alternative ways. The first consists in examining the aggregate male and female networks constructed by merging all sequence networks of people of the same gender. In these networks, line values represent the numbers of individual itineraries in which a given event sequence occurs (see Fig. 7, where line values are indicated by different line widths). Table 5 provides some basic indicators for the network position of the various types of relations.

\footnotetext{
${ }^{14}$ See above footnotes 11 and 12.
} 


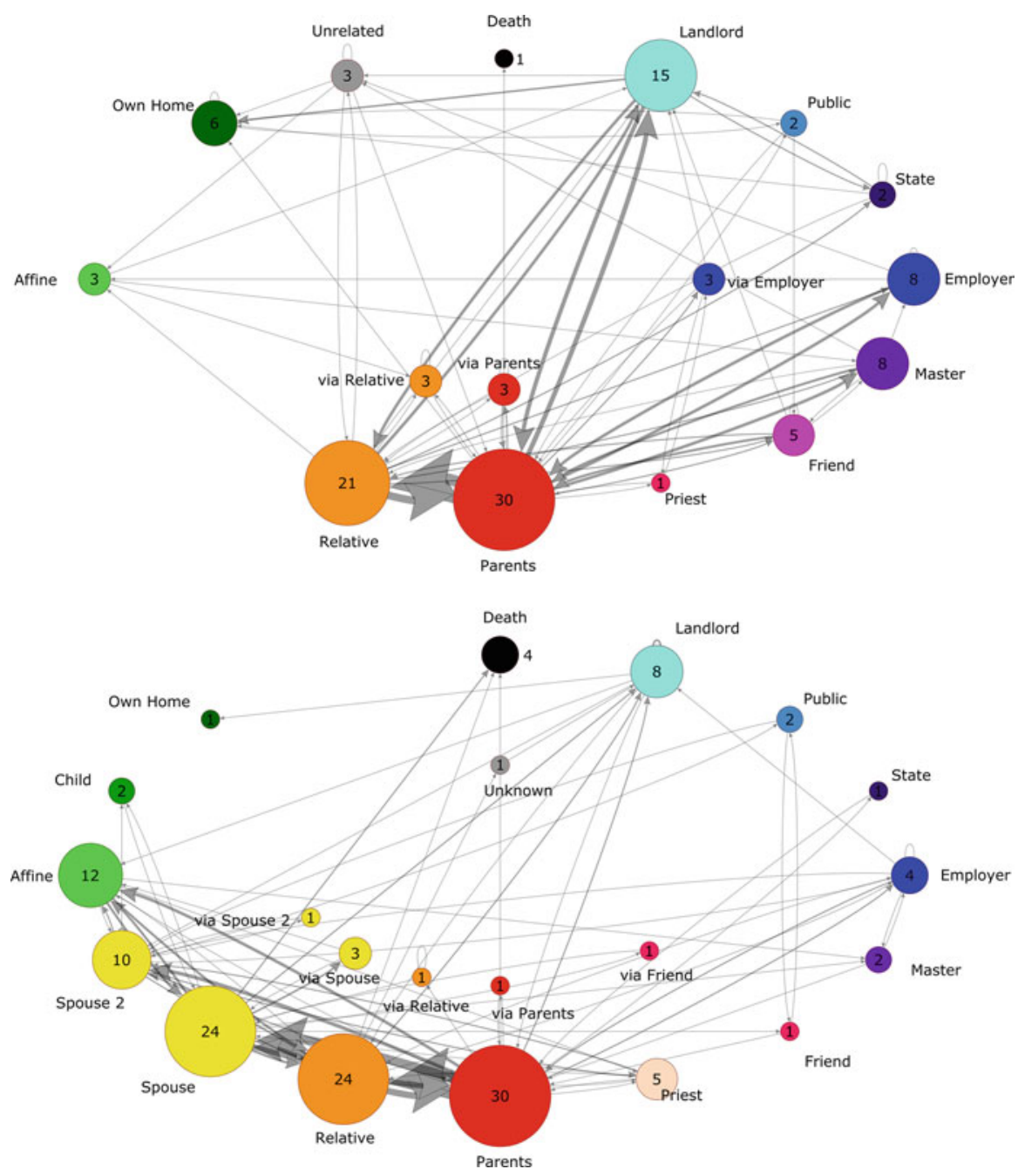

Fig. 7 Aggregate sequence networks of men (top) and women (bottom) (initial random sample, $n=30$ each). For the color code see Fig. 4

As our four examples have already suggested, both male and female networks are centered around a fundamental axis linking parents and non-parental relatives. Not only are relatives the most frequent successors of parents as hosts (which is partly accounted for by the widespread practice of fosterage), but a person who has been hosted by a relative is also likely to return to the parental home. For both men and women, a stay with relatives provides the springboard for engaging in monetarized relations with landlords, which then tend to replicate themselves. However, men enter two times as frequently into relations with landlords than 
Table 5 Basic indicators of the position of social relation types in male and female aggregate sequence networks: number of individual networks containing nodes of this type, normalized inand outdegree and betweenness centrality of the node in the aggregate network (initial random sample, $n=60$ )

\begin{tabular}{l|l|l|l|l|l|l|l|l}
\hline & \multicolumn{3}{l}{ Occurrences } & \multicolumn{2}{l|}{ Indegree } & \multicolumn{2}{l}{ Outdegree } & \multicolumn{2}{l}{ Betweenness } \\
\cline { 2 - 10 } & M & F & M & F & M & F & M & F \\
\hline Parents & 30 & 30 & 75.0 & 57.1 & 81.3 & 57.1 & 46.24 & 34.58 \\
\hline Relative & 21 & 24 & 56.3 & 38.1 & 68.8 & 47.6 & 17.63 & 9.8 \\
\hline Landlord & 15 & 8 & 50.0 & 28.6 & 37.5 & 28.6 & 8.56 & 10.07 \\
\hline Spouse & & 24 & & 42.9 & & 52.4 & & 29.78 \\
\hline Spouse 2 & & 10 & & 42.9 & & 42.9 & & 18.7 \\
\hline Child & & 2 & & 9.5 & & 4.8 & & 0.45 \\
\hline Affine & 3 & 12 & 18.8 & 33.3 & 18.8 & 33.3 & 1.31 & 5.47 \\
\hline Employer & 8 & 4 & 25.0 & 23.8 & 25.0 & 28.6 & 1.42 & 2.32 \\
\hline Master & 8 & 2 & 25.0 & 14.3 & 31.3 & 9.5 & 1.07 & \\
\hline Own home & 6 & 1 & 37.5 & 4.8 & 12.5 & & 2.79 & 2.06 \\
\hline Friend & 5 & 1 & 31.3 & 9.5 & 31.3 & 9.5 & 3.07 & 0.49 \\
\hline Priest & 1 & 5 & 12.5 & 19.0 & 12.5 & 19.0 & & 0.45 \\
\hline Public & 2 & 2 & 12.5 & 9.5 & 18.8 & 9.5 & 6.67 & 1.1 \\
\hline State & 2 & 1 & 18.8 & 4.8 & 25.0 & 4.8 & 0.12 & \\
\hline Unknown & & 1 & & 4.8 & & 4.8 & & \\
\hline Unrelated & 3 & & 31.3 & & 31.3 & & & \\
\hline Death & 1 & 4 & 6.3 & 14.3 & & & 1.47 & \\
\hline
\end{tabular}

do women, and are also more than twice as likely to progress from a stay with relatives to a rented apartment. The most significant difference is, of course, the importance of marital homes for female itineraries, this having no equivalent in their male counterparts. Note, however, that these spouse-linked positions are far from representing endpoints: their outdegrees exceed or equal their indegrees; in other words, the positions they lead to are more diverse than those that lead to them, indicating continuing residential mobility. Also note that the parental home, followed by relatives' homes, is the most frequent base from which women (re)join their first and subsequent husband(s) - it is extremely rare for women to move directly from one husband to another.

To sum up, the aggregate female sequence network, rather than being totally distinct from the male network, represents a variant of it, rendered more complex by the integration of one or more additional focal nodes. While the typical male network is largely organized around a triangle formed by the parental home, relatives and the residential market, the female network contains in addition one or more spouse nodes, which may become the nuclei of marital subnetworks. As a consequence, the relative importance of the various focal nodes (as measured by their betweenness centrality) differs between male and female networks. In male networks, the parental home clearly constitutes the dominant central node-as might be expected in a rural environment with agnatic transmission of land rights- 
while in female networks, it shares importance with the almost equally central first marital home, followed by subsequent marital homes.

The problem with this kind of comparative macro-analysis is, of course, that it already presupposes that gender is a pertinent classification criterion for merging individual sequence networks, instead of deriving the classification criteria from a comparative analysis at the micro-level of individual sequence networks. This latter perspective characterizes the approach of optimal matching analysis (Abbott 1995) and its more recent network-analytic analogues, where sequence matching is replaced by graph similarity (Butts and Pixley 2004; Butts 2008; Fitzhugh et al. 2015). Since in our relational sequence networks each node type appears, by construction, at most once in each network (the only quasi-exception being first and subsequent spouses, which we have treated as distinct types), we can construct all sequence networks with identical node sets (absent nodes being left unconnected), so that the only edit operations necessary to transform one network into another consist in adding or removing arcs. Graph edit distance thus boils down to the (normalized) number of differently connected pairs of nodes (that is, the number of different cells in the adjacency matrices of the two graphs). Based on this graph distance matrix, hierarchical clustering techniques can be applied to represent the similarities and differences of the relational sequence networks. Figure 8 displays the agglomerative clustering tree of the 60 sequence networks of the initial random sample, constructed by the neighbor-joining algorithm (Saitou and Nei 1987), ${ }^{15}$ and spatialized by the Kamada-Kawai spring embedded algorithm implemented in Pajek. The graphs of the individual sequence networks have been plotted into the nodes of the tree, and border colors indicate gender (blue for male and red for female). Our four example cases are emphasized by the use of grey shades.

While the gender difference is neatly brought out by the graph (roughly speaking, female itineraries are located in the upper half, male itineraries in the lower half of Fig. 8), a closer look shows that, beyond the great divide introduced by virilocality (the presence or absence of "yellow" marital nodes in the sequence network), both male and female sequence networks are differentiated into several branches of the tree.

Most sequence networks, irrespective of gender, are based on the parent-relative axis, to which the simplest of them (such as Aloesso's) may reduce. In the "male" case, this basic axis frequently combines either with rent (as for the urban migrant workers), with hosting by the master or employer (as for the rural itinerary masons or woodcutters), or with both. This combination, eventually enriched by marital nodes, may also characterize the sequence networks of female domestic workers (such as Betty). A still more complex variant, characteristic of teachers' itineraries, combines rented accommodation with lodging by the state. Finally, the itinerary

\footnotetext{
${ }^{15}$ The neighbor-joining algorithm consists in sequentially linking the two nearest neighbors to a newly created "ancestor" node and recalculating the distances of all other nodes to the ancestor node from their distances to the joined neighbor nodes. Pairwise distances are adjusted by the average distance of both neighbors to the rest of the network. In Fig. 8 ancestor nodes are only represented as bifurcation points of outgoing arcs.
} 


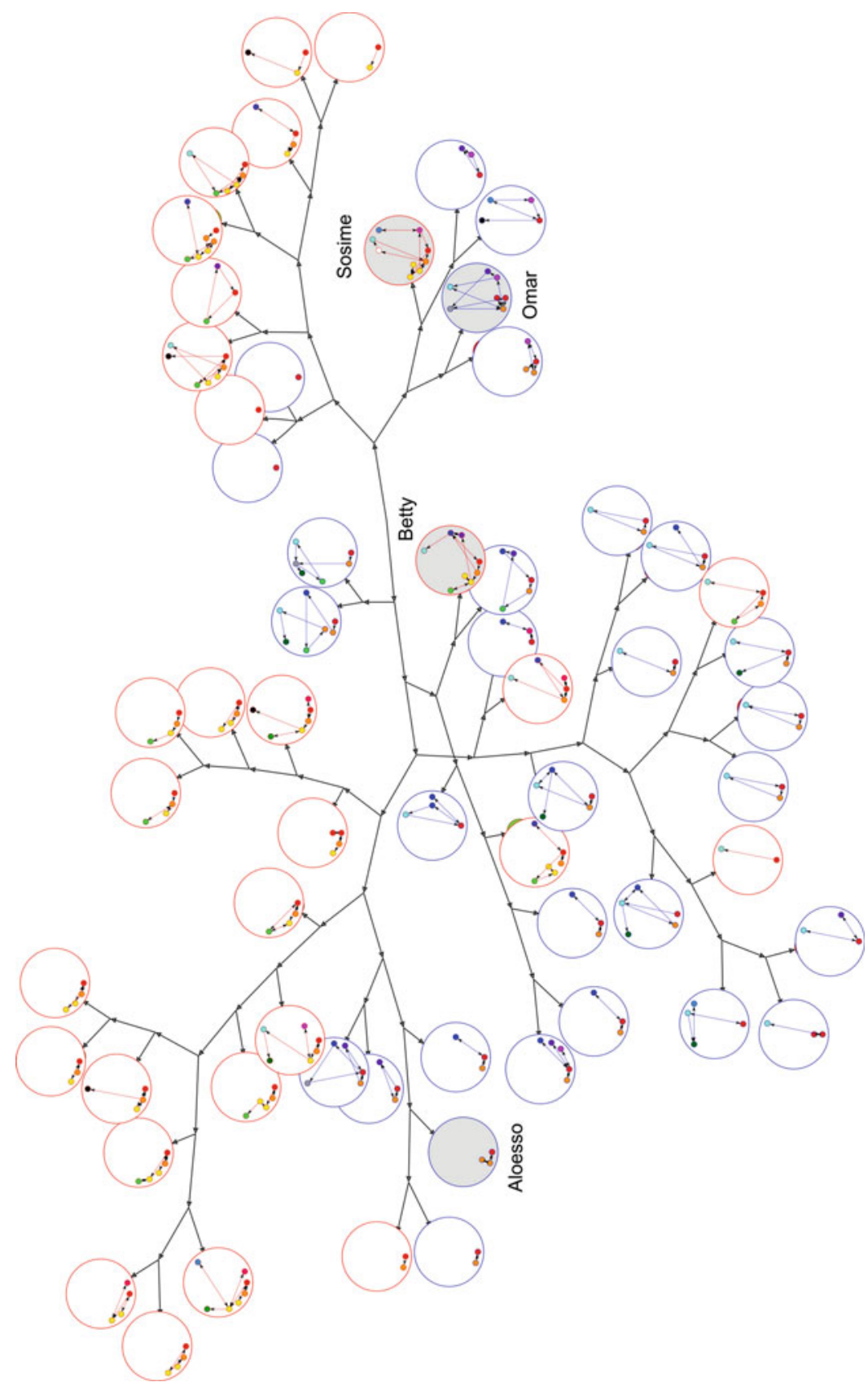

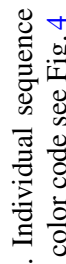

घ

훙

त)

bo

음

뭉

당

¿

ए

อे

क न

존

롱

힐

500

을

氙

ฮ

0 ว

ิㅡㅇ

ํำ

늘

45

के

范

究

$\Rightarrow$

:

छ

館

8 운

$\stackrel{\Xi}{\Xi}$

4

ญ.

कo :

.

인

코

$\infty$ 항

$\infty$ 
may involve lodging by friends or unrelated persons, frequently in a transnational context, as exemplified by Omar's case. Again, this pattern may be equally found among female traders (such as Sosime). A quite different type of itinerary is located at the bottom left of the tree, where the parental node is directly linked to the landlord node without passing through a relative's home. This is a minority pattern generally restricted to men who have migrated later in life for professional reasons, and to the few boys whose parents could afford to rent apartments for them while they attended high school. However, we also find this itinerary present in two women who chose not to marry.

While all the predominantly "male" patterns of sequence networks are accessible to women, the "female" upper half of the graph is significantly more homogenous. The upper left part in particular is made up of a large group of highly similar sequences completing the parent-relative-axis by one or more marital or affinal nodes, thus giving rise to several distinct clusters according to the complexity of the marital subnetwork. This pattern may further evolve by integrating stays with landlords, masters or employers (mainly for trade or domestic work), as can be seen on the upper right side (actually a female enclave encompassed by predominantly male patterns). By contrast, we almost never find a female pattern without the "relative" node in it. Women who leave their parental home directly for a rented apartment are even more rare then men (though, also here, the exception proves the rule).

\section{Conclusion}

Our analysis of the topology of both personal and sequence networks has produced convergent results with regard to the logics underlying gendered mobility patterns in South-east Togo. Male and female sequence networks both rest on a basic kinship axis (linking an "internal" parent pole and an "external" extended-kinship pole). For both genders (though more so for men), the parental home is a central place of (definitive or transitory) return, and for both genders, relatives outside the immediate family circle play an equal (for women even a stronger) role than parents, in particular before the age of marriage. The simplest migration pattern, and the starting point for most male and female itineraries, is an oscillation between parents in the village and relatives beyond.

The main difference between the genders consists in the way their respective social sequence networks develop from this double kinship core. Due to the sexual division of labor which renders wage-labor still an essentially male domain (women are either independent traders or work for relatives as domestic workers and market assistants), and to the virilocal residence rule, according to which women at least initially join their husbands' home, the networks of men tend to evolve through nonkinship links to friends, masters, employers, strangers or landlords, while women's networks grow through the emergence of affinal links to spouses and in-laws. 
This difference is not only one of relational circuits but also of network morphology. Male non-kin relations, often radiating from the core in a star-like manner, are generally multiple but socially disconnected (except when they are linked to the kinship complex). By contrast, female affinal relations, though less numerous, are structurally productive: they develop into larger subnetworks that may succeed each other as disjoint spheres or merge into an integrated space of circulation. While male networks thus tend to evolve through a succession of structurally isolated non-kinship links, female networks develop into complex multifocal networks sewn together by marital and affinal ties-that is, the very ties that link together male and female itineraries. In other words, the central source of difference between the sequence networks of men and women is precisely their mutual relation.

Rather than just confirming the macro-tendencies for male and female mobility patterns (as stated in the demographic literature) at the micro-level of individual trajectories, sequence network analysis yields insight into the relational logics that bring these tendencies about. It serves not only to study the differences between gendered social networks, but also to understand gender itself as a relation between networks, that is, not just as an attribute of individuals, but as a structural trait of social space-time. In a more general perspective, the nascent integration of network and sequence analysis may be the first step towards a full-fledged social topology.

Acknowledgements The paper is part of a larger research project conducted with Karin Sohler since 2010. Preliminary results were the subject of joint presentations at the 1st European conference of Social Network Analysis in Barcelona in 2014 and at the 3rd meeting RéseauxHistoire in Paris in 2015. Though Karin did not coauthor the present paper, its argument owes a fundamental debt to our collaborative work. I am also grateful to Véronique Hertrich, Ismaël Moya, Sorana Toma, Claire Lemercier and Karen Middleton, as well as to the anonymous reviewers of the LaCOSA II conference and for this volume, for their valuable and encouraging comments on earlier versions of this paper.

Fieldwork has been supported by the Laboratoire d'Anthropologie Sociale, the EHESS research fund and the French Cooperation in Togo. The 2010 fieldwork was carried out in cooperation with Ibitola Tchitou and Kokou Vignikin from the Unité de Recherche Démographique of Lomé University. This work would have been impossible without the competence and dedication of my field collaborators Komi Malou Kakanou and Toussaint Yakobi and the active cooperation and help of the interviewees, to whom I present my heartfelt thanks.

The sequence-network module of Puck has been developed with Christian Momon as part of the project "Kinsources" supported by the French National Research Agency ANR (research grant ANR-12-CORP-0008).

\section{References}

Abbott, A. (1995). Sequence analysis: New methods for old ideas. Annual Review of Sociology, 21(1), 93-113.

Abbott, A. (1997). Of time and space: The contemporary relevance of the Chicago School. Social Forces, 75(4), 1149-1182. 
Batagelj, V., \& Mrvar, A. (2008). Analysis of kinship relations with Pajek. Social Science Computer Review, 26(2), 224-246.

Bearman, P. S., Faris, R., \& Moody, J. (1999). Blocking the future: New solutions for old problems in historical social science. Social Science History, 23(4), 501-533.

Bearman, P. S., \& Stovel, K. (2000). Becoming a Nazi: A model for narrative networks. Poetics, 27(2), 69-90.

Bison, I. (2014). Sequence as network: An attempt to apply network analysis to sequence analysis. In P. Blanchard, F. Bühlmann, \& J.-A. Gauthier (Eds.), Advances in sequence analysis: Theory, method, applications (pp. 231-248). Cham: Springer.

Butts, C. T. (2008). A relational event framework for social action. Sociological Methodology, 38(1), 155-200.

Butts, C. T., \& Pixley, J. E. (2004). A structural approach to the representation of life history data. The Journal of Mathematical Sociology, 28(2), 81-124.

Cordell, D. D., Piché, V., \& Gregory, J. W. (1996). Hoe and wage: A social history of a circular migration system in West Africa. Boulder: Westview Press.

Cordonnier, R. (1987). Femmes africaines et commerce: Les revendeuses de la ville de Lomé (Togo). Paris: l'Harmattan.

Cornwell, B. (2015). Social sequence analysis: Methods and applications, Volume 37 of Structural analysis in the social sciences. Cambridge: Cambridge University Press.

Cornwell, B. (2018). Network analysis of sequence structures. In G. Ritschard \& M. Studer (Eds.), Sequence analysis and related approaches: Innovative methods and applications. Cham: Springer (this volume).

Cornwell, B., \& Watkins, K. (2015). Sequence-network analysis: A new framework for studying action in groups. In S. R. Thye \& E. J. Lawler (Eds.), Advances in group processes (Vol. 32, pp. 31-63). Bradford, U.K: Emerald Group Publishing Limited.

Fitzhugh, S. M., Butts, C. T., \& Pixley, J. E. (2015). A life history graph approach to the analysis and comparison of life histories. Advances in Life Course Research, 25, 16-34.

Freeman, L. (1977). A set of measures of centrality based on betweenness. Sociometry, 40(1), 35-41.

Hamberger, K. (2011). La parenté vodou: Organisation sociale et logique symbolique en pays ouatchi (Togo). Paris: CNRS Éditions, Éditions de la Maison des sciences de l'homme.

Hamberger, K., Grange, C., Houseman, M., \& Momon, C. (2014). Scanning for patterns of relationship: Analyzing kinship and marriage networks with Puck 2.0. The History of the Family, 19(4), 564-596.

Hamberger, K., Houseman, M., \& White, D. (2011). Kinship network analysis. In J. Scott \& P. J. Carrington (Eds.), The SAGE handbook of social network analysis (pp. 533-549). London: SAGE.

Liu, M.-M. (2013). Migrant networks and international migration: Testing weak ties. Demography, 50(4), 1243-1277.

Locoh, T., \& Thiriat, M.-P. (1995). Divorce et remariage des femmes en Afrique de l'Ouest. Le cas du Togo. Population (French Edition), 50(1), 61-93.

Lubbers, M. J., Molina, J. L., Lerner, J., Brandes, U., Ávila, J., \& McCarty, C. (2010). Longitudinal analysis of personal networks: The case of Argentinean migrants in Spain. Social Networks, 32(1), 91-104.

Pilon, M., \& Ségniagbéto, K. (2014). Confiage, domesticité et apprentissage à Lomé à la veille de l'indépendance. Journal des Africanistes, 84(1), 212-247.

Saitou, N., \& Nei, M. (1987). The neighbor-joining method: A new method for reconstructing phylogenetic trees. Molecular Biology and Evolution, 4(4), 406-425.

Stark, D., \& Vedres, B. (2006). Social times of network spaces: Network sequences and foreign investment in Hungary. American Journal of Sociology, 111, 1367-1411. 
Stark, D., \& Vedres, B. (2012). Social sequence analysis: Ownership networks, political ties, and foreign investment in Hungary. In J. F. Padgett \& W. W. Powell (Eds.), The emergence of organizations and markets (pp. 347-374). Princeton: Princeton University Press.

Wissink, M., \& Mazzucato, V. (2018). Transit: Changing social networks of sub-Saharan African migrants in Turkey and Greece. Social Networks, 53, 30-41.

Open Access This chapter is licensed under the terms of the Creative Commons Attribution 4.0 International License (http://creativecommons.org/licenses/by/4.0/), which permits use, sharing, adaptation, distribution and reproduction in any medium or format, as long as you give appropriate credit to the original author(s) and the source, provide a link to the Creative Commons license and indicate if changes were made.

The images or other third party material in this chapter are included in the chapter's Creative Commons license, unless indicated otherwise in a credit line to the material. If material is not included in the chapter's Creative Commons license and your intended use is not permitted by statutory regulation or exceeds the permitted use, you will need to obtain permission directly from the copyright holder. 